\title{
Extranasopharyngeal angiofibroma in an adolescent male: a case report
}

\section{Lourdes Albina Siluvai Arulappan*}

\author{
Upgraded Institute of ORL, Madras Medical College, Chennai, India
}

Received: 16 May 2019

Revised: 04 July 2019

Accepted: 11 July 2019

\section{*Correspondence:}

Dr. Lourdes Albina Siluvai Arulappan,

E-mail: albinathegr8t@gmail.com

Copyright: (C) the author(s), publisher and licensee Medip Academy. This is an open-access article distributed under the terms of the Creative Commons Attribution Non-Commercial License, which permits unrestricted non-commercial use, distribution, and reproduction in any medium, provided the original work is properly cited.

\section{ABSTRACT}

A 16 year old male presented with complaints of obstruction in the right side of nose for 15 days, 4 episodes of unprovoked bleeding from right nasal cavity for one week. The epistaxis was sudden in onset. CT revealed polypoidal mass in the right nasal cavity, filling inferior $1 / 3 \mathrm{rd}$ of the right anterior nasal cavity, with attachment to the nasal septum. Endoscopic excision of the mass was done in toto and histopathological examination report showed it to be an extra nasopharyngeal angiofibroma.

Keywords: Angiofibroma, Extra nasopharyngeal, Sphenopalatine foramen

\section{INTRODUCTION}

Angiofibromas commonly arises in the nasopharynx. Though the JNA are histologically benign, it clinically belongs to clinically threatening due to its bleeding. ${ }^{1}$ The tumour most commonly arises from the lateral all of the nasal cavity close to sphenopalatine foramen and pterygoid base. It has been proposed that the tumour region is based on an incomplete regression of first branchial arch artery. ${ }^{2}$ In 1980 , de Vincentus studied a series of 704 cases of angiofibroma, in which 13 cases manifested outside nasopharynx. ${ }^{3}$ Extra nasopharyngeal angiofibromas differ from that it affects older and symptoms develop more quickly, incidence is more and hypervascularity is less. Most common site of extra nasopharyngeal angiofibroma is maxillary sinus with $32 \%$ of incidence; ethmoid sinus,nasal septum, nasal cavity, larynx, sphenoid sinus, conjunctiva, oropharynx, middle cranial fossa, infratemporal fossa, hypopharynx, facial nerve, lacrimal sac, retromolar area, middle turbinate, inferior turbinate, trachaea and esophagus. ${ }^{4-8}$ Angiofibroma is a benign lesion of the nasopharynx in adolescent males. It is a mesenchymal neoplasm histopathologically showing abundant fibrous stroma with fatal vascular structures devoid of muscle coat. It is not an exclusive tumour of nasopharynx and can also occur outside the nasopharynx which is termed as extra nasopharyngeal angiofibroma. These lesions are often missed due to its rarity and different anatomical location.

\section{CASE REPORT}

A 16 year old male had obstruction in the right side of nose for 15 days. 4 episodes of unprovoked bleeding from right nasal cavity for one week was observed. The epistaxis was sudden in onset, there was 5-10ml bleeding in each episode. No nasal packing was required for epistaxis.

On examination, external contour were normal. Anterior rhinoscopy-septum deviated to left, smooth reddish polypoidal mass was found attached to the middle part nasal septum seen in the right nasal cavity (Figure 1). The mass was sensitive to touch and bled. There was no reduction in size upon decongestion. Posterior rhinos copy was normal. Ear and throat were clinically normal. 


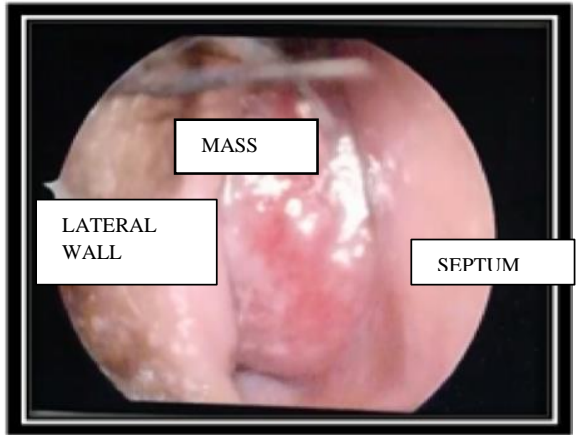

Figure 1: Anterior rhinoscopy.

CT revealed polypoidal mass in the right nasal cavity, filling inferior $1 / 3 \mathrm{rd}$ of the right anterior nasal cavity, with attachment to the nasal septum (Figure 2).

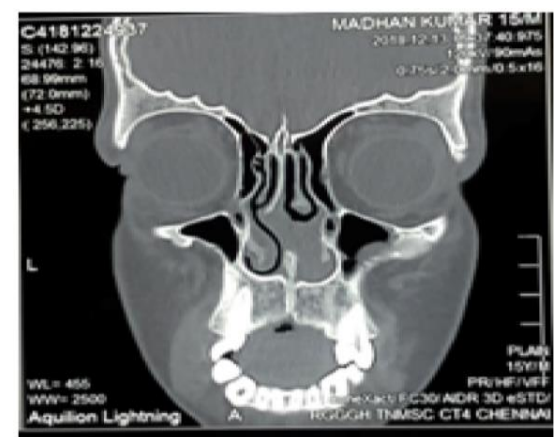

Figure 2: Pre operative CT.

MRI showed sausage shaped polyp present in the anterior nasal cavity extending to the nares (Figure 3).

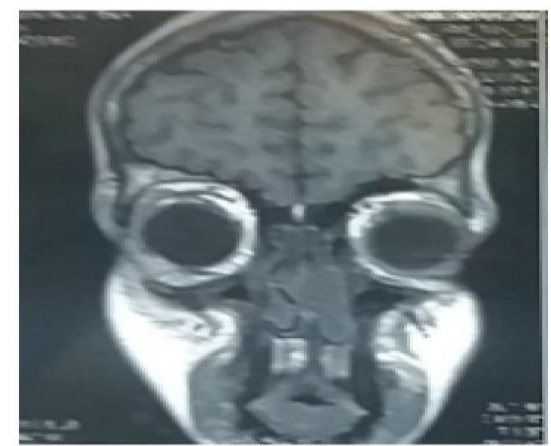

Figure 3: Preoperative MRI.

Endoscopically the mass was excised in toto (Figure 4) and histopathological examination report showed it to be an extranasopharyngeal angiofibroma with section showing psuedostratified columnar epithelium with squamous metaplasia. The underlying neoplasm composed of numerous blood vessels with variable vessel wall thickness lined by flattened endothelium filled with RBCs.

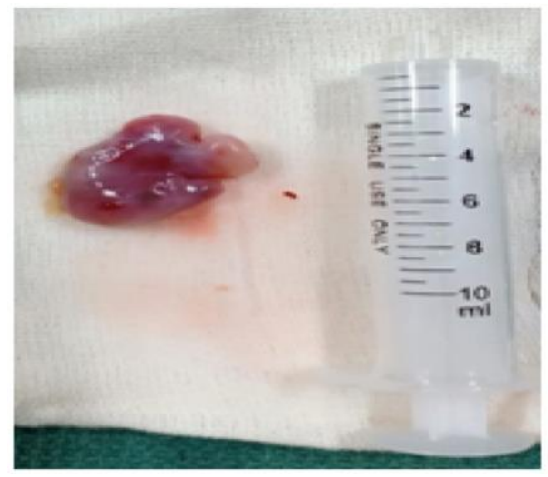

Figure 4: Excised specimen.

Variable smooth muscle coat admixed with stellate fibroblasts which are spindle shaped with spindle shaped nuclei with a moderate cytoplasm in a edematous and myxoid stroma (Figure 5,6). Patient was followed up regularly and $\mathrm{CT}$ was taken postoperatively in the third month (Figure 7). ${ }^{9}$

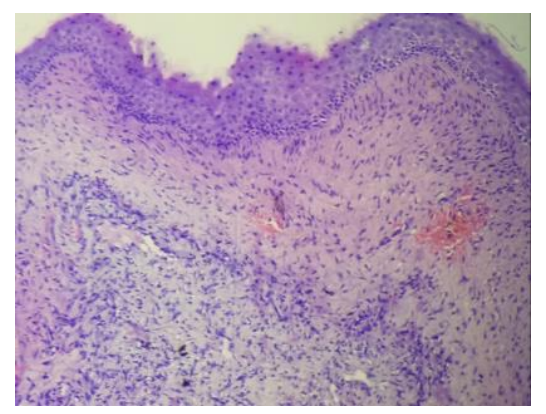

Figure 5: HPE (low power).

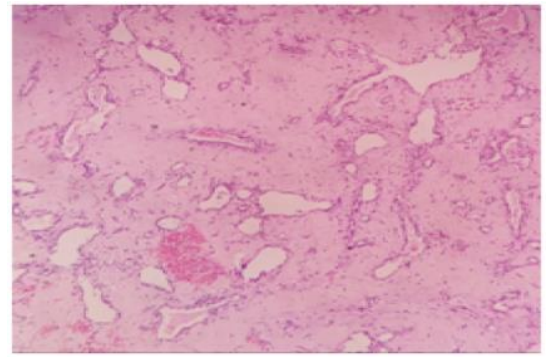

Figure 6: HPE (high power).

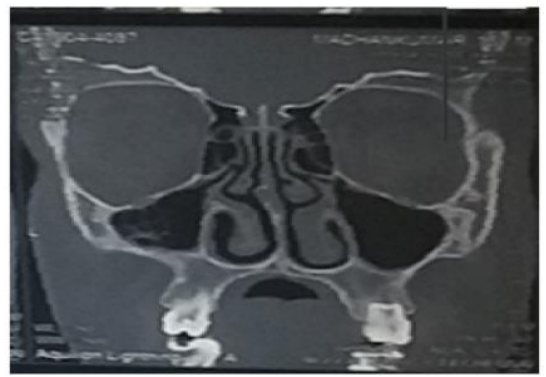

Figure 7: Post-operative CT. 


\section{DISCUSSION}

Nasopharyngeal angofibroma is a well known tumour of adolescent males. The tumour arises from the nasopharynx and then later extend into the neighbouring structures. Recently extranasopharyngeal angiofibroma is the term given to the vascular, fibrous nodules occuring outside the nasopharynx. ${ }^{10}$ These tumours which do not arise from the vicinity of the sphenopalatine foramen or pterygoid base are coined as extranasopharyngeal (ENA). ${ }^{11}$ JNA are benign, unencapsulated fibrovascular lesions that account for less than $0.5 \%$ of all head and neck tumours. ${ }^{12}$ The mean age of presentation of extranasopharyngeal angiofibroma is 22 years and male to female ratio is $3: 1$. This is in contrast to nasopharyngeal angiofibroma which is exclusively present in adolescent males with mean age range between 14 and 17 years;female presentation is rare. ${ }^{13}$ It was suggested that embryonic ectopic remnants during the development of nasal septum was the cause for the origin of septal ENA. ${ }^{14}$ There was a slight preponderence to the right. 15

Alvi et al considered CT scan to be sufficient for the diagnosis of extra nasopharngeal angiofibroma, as it clearly delineates the tumour. CECT and MRI are used to determine the site and its extension, with special attention being focussed on skull base involvement, intracranial spread and relationship to important vascular and neurological structures. ${ }^{16}$

\section{CONCLUSION}

I conclude that in an unilateral torrential nasal bleeding, extra nasopharyngeal angiofibroma to be considered as a differential diagnosis irrespective of age and gender. As the presentation of these angiofibromas are rare,it should not be missed due to its paucity of literature and lack of standardized management.

Funding: No funding sources Conflict of interest: None declared

Ethical approval: Not required

\section{REFERENCES}

1. Wigand ME. Endoscopic surgery of paranasal sinus and anatomy of skull base. 2nd ed. Thieme; 2019: 193.

2. Scott Brown's Otorhinolaryngology, Head and Neck surgery. Watkinson JC, Clarke RW, eds. 8th ed. Volume 1. Basic sciences, Endocrine Surgery and Rhinology: 1265-1266.
3. de Vincentis G, Pinelli V. Rhinopharyngeal angifibroma in the pediatric age group.Clinical statistical contribution. Int $\mathbf{J}$ Pediatric Otorhinolaryngol.1980;2:99-122.

4. Huang RY, Damrose EJ, Blackwell KE, Cohen AN, Calceterra TC. Extranasopharyngeal angiofibroma. Int J Ped Otorhinolaryngol. 2000;56:59-64.

5. Windfuhr JP, Remmert S. Extranasopharyngeal angiofibroma: etiology, incidence and management. Acta Otolaryngol. 2004;124:880-9.

6. Dogan S, Yazici H, Metin M, Soy FK. Extra nasopharyngeal angiofibroma of the nasal septum: a rare clinical entity. J Craniofacial Surg. 2013;24(4):390-3.

7. Singh G, Shukla S, Kumari P, Shukla I. A rare case of extra nasopharyngeal angiofibroma of the septum in a female child. J Laryngol Otol. 2018;132:184-7.

8. Bhagat $\mathrm{S}$, Verma $\mathrm{R} K$ Panda $\mathrm{N}$. Extranasopharyngeal angiofibroma in an adult: a rare presentation. Indian J Otolaryngol Head Neck Surg. 2011;63(1):25-6.

9. Tasca I. Extranasopharyngeal angiofibroma of nasal septum: a controversial Entity. Acta Otorhinolaryngologica Italica 2008;28:312-4.

10. Szymanska A. Extranasopharyngeal angiofibroma: Clinical and radiological presentation. Eur Arch Otorhinolaryngol. 2013;270:655-60.

11. Sarpa JR, Novely NJ. Extranasopharngeal angiofibroma. Otolaryngol Head Neck Surg. 1989;2:99-122.

12. Tang P, Shashinder S, Gopala G, Narayanan P. Juvenile Nasopharyngeal angiofibroma in a tertiary centre: ten year experience. Singappore Med J. 2009;50(3):261.

13. Peloquin L, Klossec JM, Vass-Brusa F. A rare case of nasopharyngeal angiofibroma in a pregnant women. Otorhinolaryngol Head Neck Surg. 1997;117(6):111-7.

14. Akbas Y, Anadolu Y. Extranasopharyngeal angiofibroma of head and neck in women. Am J Otolaryngol. 2003;24:413-6.

15. Dubey SP, Schick B. Juvenile Angiofibroma. Germany: Springer; 2017: 267.

16. Alvi A, Myssiorek D, Fuchs. An extranasopharyngeal angiofibroma. $\mathrm{J}$ otolaryngol. 1996;25:346-8.

Cite this article as: Arulappan LAS. Extranasopharyngeal angiofibroma in an adolescent male: a case report. Int $\mathbf{J}$ Otorhinolaryngol Head Neck Surg 2019;5:1416-8. 